\title{
Writing Groups in Computer Science Research Labs
}

\author{
Adam Doupé and Janet L. Kayfetz \\ University of California, Santa Barbara \\ \{adoupe,kayfetz\}@cs.ucsb.edu
}

\begin{abstract}
Researchers must excel at writing to effectively engage the scientific community. Clear and engaging writing advances new knowledge and increases the impact of a researcher's work.

As developing researchers, it is essential that graduate students learn to write clearly and effectively so that their work is accessible to their peers and colleagues. An essential part of graduate school education should include the teaching of formal writing skills. In most graduate programs, students learn formal writing skills from two sources, their advisors or a writing class. We identify a third source: the graduate student peer group. In this paper, we describe how we leveraged the existing collaborative research dynamic among students in a graduate research lab and created a writing group, similar in spirit to the concept of a reading group.
\end{abstract}

We describe the inspiration, implementation, and impact of a writing group in a real-world research lab. We show how the writing group started organically after a PhD student took a graduate writing class in the Computer Science Department and thereafter initiated the writing group in his research lab. We also describe how a writing group can be implemented in other research labs to improve the writing of graduate students worldwide.

\section{INTRODUCTION}

Ask any established researcher and she will tell you just how important writing skills are for being a successful researcher and scientist. It is through our writing that we achieve one of our main goals: To spread our ideas to our colleagues and to the general public. Some of the main vectors for the spread of ideas are through written research papers, journal articles, book chapters, email communications, posters, and magazine and newspaper articles, all of which, we hope, are read by our peers.

Graduate students are the next wave of researchers and scientists, and it is our job as educators and advisors to instruct graduate students on all aspects of the research endeavor. We do an excellent job of teaching our students to carry out scientifically sound research, but are we doing an equally excellent job in the related areas of graduate study? In particular, are we teaching our graduate students how to write and communicate their ideas effectively? Do we illuminate all of the components of the writing process and give students the tools for excellent writing?

Excellent writing skills are vital for graduate student success. Great writing can increase the chances that a student's paper is accepted for publication, increase the impact of the student's work, and hopefully increase the number of citations of the student's work. However, more importantly, writing skills provide students with a base of knowledge that will benefit them regardless of their career trajectory-writing skills are equally valued in academia, in industry, in government, and in entrepreneurial ventures.

Traditionally, graduate students learn formal writing skills from interactions with their advisors, either in the form of redink editing corrections on a student's manuscript or one-on-one mentoring. A second way that graduate students learn formal writing skills is by participating in an academic writing class focused on the rhetorical demands of science writing [1].

But there is a third source where graduate students can learn formal writing skills- their peer group. In addition to developing the skills of research design and data interpretation, the graduate student peer group provides the ideal social dynamic for the discussion of writing. Building on the culture of group analysis and discussion that already exists in the graduate student research lab, we created and introduce here the concept of a research lab writing group, inspired by the idea of the reading group, a common activity in many science research labs.

In the research lab writing group, graduate students not only learn the techniques of formal writing from their peers, they also learn the writing and research norms of their specific research field. Students also gain insights into how other students in their lab approach the writing process.

In this paper, we present the concept of a research lab writing group and describe the high-level goals that such a group should achieve. We also describe the structure of the writing group and the roles and behaviors of the group leader, the authors, and the audience. Our discussion is meant to inspire other graduate students and their advisors to start their own writing groups, thus improving graduate student writing skills in graduate research labs all around the world.

\section{IDEA GERMINATION}

The writing group concept came about after a PhD student completed a graduate-level academic writing course for scientists offered by the Computer Science Department at the University of California, Santa Barbara [1]. After attending the class and soaking up all the writing skills that were offered [2], the student wished to share this knowledge with his fellow graduate students in his research lab.

The student modeled the writing group concept after a common practice in his lab: the reading group. For those who are not familiar, a reading group is a common activity among research labs. The purpose of a reading group is to stay on top of newly published research in a specific field. In most formats, one student is selected to present a research paper to the rest of the group. Most reading group formats meet weekly from 30 minutes to an hour. The student presenting the paper begins by leading the group through an overview of the paper. The 
presenter then moderates a discussion of various aspects of the paper, including the positive contributions of the research, the appropriateness of the topic for the venue, experimental design, weaknesses in any aspect of the work, and future research work related to the paper.

The aspects of a reading group that we wish to capture in the writing group are the weekly meeting format, the group discussion, and the rotation of student presenters.

We have been running our writing group for 20 weeks in a real-world computer security research lab with $14 \mathrm{PhD}$ students and five interns. Participation is completely voluntary and peer-motivated. Importantly, while the faculty advisors of the research lab encourage the idea, they do not attend the writing group - the creation of the group, the attendance, and the interactive discourse are $100 \%$ student driven.

The writing group initially lasted for nine weeks, one week short of the standard 10-week quarterly course. The group went on hiatus after the first 9 weeks, not because of a lack of interest from the students, but because the leader left for a summer internship. Interestingly, as a direct result of writing this paper, the students in the research lab were motived to reestablish the writing group. The second phase of the writing group has been continuing successfully for 11 weeks and is still going strong.

\section{GOALS}

When developing the design of the writing group, we had multiple goals in mind.

To improve the writing of the research lab. It may seem obvious, but our goal, first and foremost, is to enhance the writing of the graduate students in the research lab. We want to foster a culture of writing excellence and support each other through the difficulties of the writing process. We also want to build the confidence of the students and help nonnative English speakers develop advanced English writing skills.

To maximize participation. We want to maximize the number of graduate students who attend the writing group. This increased participation is important for two reasons. First, the more people who attend the meetings, the more impact we can have on their writing. Second, because the writing group is a collaborative meeting, the group as a whole benefits from having the perspective from the most number of students.

To maximize interaction among the participants. We see interaction during the meeting as being different from simply showing up. It is one of our explicit objectives to encourage each lab member to share her ideas and opinions. In addition to looking at writing, we also hope that participants feel increased confidence in their ability to analyze and discuss a research text.

To develop core writing skills as well as a successful and useful approach to the analysis and discussion of texts. Our purpose is to impart the concepts and vocabulary taught in a formal academic writing class, including rhetorical positioning, audience, purpose, development of the problem space, data commentary, clarity, tone, register, coherence, transitions, readability, and so on [3], [4]. We also want to focus on the important sub-genres of a science text like abstracts, introductions, data commentaries and results, literature review, and conclusions.

To be focused on current writing tasks. We want our writing group to focus on current writing tasks so that we can have a direct impact on the quality of the texts produced by lab members. This focus increases the relevance for group members because we look at real texts instead of contrived writing samples. By doing real work, we see increased attendance in the writing group as students are offered the opportunity to read and review current work by their peers.

To spread knowledge among the group about the ways to structure and write about research issues that are idiosyncratic to our area of Computer Science research. We want to make sure that all lab members are aware of the norms and subtleties of science discourse in our specific subfield. These subtleties apply not only to issues such as paper structure, but also to research design and research focus.

\section{GROUP STRUCTURE}

We now turn our attention to a description of the specific mechanics of our writing group sessions. We describe the roles involved along with the format of the writing group.

\section{A. Roles}

For a writing group to operate successfully and achieve all of the goals we set out in Section III, the roles of each of the participants in the writing group should be well defined. Here, we define the roles in the writing group as we have experienced them, and in Section V we describe the suggested actions and behaviors of each of the roles.

1) Leader: The leader of the writing group is ideally a student who cares deeply about both the writing process and improving the writing of her peers. The leader should have a solid grounding in formal writing skills because it is the leader's job to teach scientific writing concepts. In our writing group, the leader had completed a class in academic writing in our Computer Science Department taught by a linguist on the Computer Science faculty. The leader is in charge of founding and starting the writing group, and preparing the lesson for each meeting.

2) Author: The author is a member of the writing group who is either selected or who volunteers to share her writing with the rest of the group. This role rotates for each meeting. Each author must get ready for the writing group beforehand by preparing her writing sample to share with the group.

3) Audience: The audience is anyone who attends the writing group meeting, excluding that session's author. Nothing is required of these students before the meeting except for an open mind, a passion to improve their writing skills, and the willingness to offer helpful feedback to peer authors. If a faculty member chooses to attend a meeting, she assumes the role of an audience member.

\section{B. Format}

We ran our writing group meetings weekly for a total of 20 weeks. To increase attendance, we made the time requirement 
manageable for the students - 30 minutes. And we kept to this time limit strictly, respecting students' busy schedules.

We worked hard to find a time that was convenient for everyone and that did not conflict with regularly-scheduled recurring meetings. Because most graduate students do not have consistent working schedules-some come in to the lab early while others come in much later-we chose a meeting time of 5 PM, as this did not conflict with any other meetings, and the time was late enough in the day that all students in the lab who wanted to attend could be present.

The 30 minutes of the writing group are broken down into two different sections. The first section, lasting ten minutes, is dedicated to teaching and discussing a specific writing concept selected by the leader, such as tone, audience, abstracts, and so on. The leader-the student who had taken the writing classintroduces the writing concept for the first few minutes, and then leads a group discussion about the specific concept.

The second phase of the writing group, lasting 20 minutes, is a group editing session of the author's writing. The author projects her writing onto a screen so that the entire audience can read the text. An important point here is that the author must prepare the text in a format that is easy to edit and change. Specifically, this means either OpenOffice or Google Docs, rather than a LTEX file that needs to be compiled. The ability of the author to edit text quickly during the group editing session is critical so that all group members can see and evaluate in real-time the changes the author is making to the piece of writing.

Figure 1 shows a real-world group editing session. The author, situated in the upper left, is facing the audience and is ready to make changes to his text. The author's text is projected onto a screen so that the author and the audience can easily read the text at the same time.

Finally, at the end of a writing group session, the leader announces next week's topic, and the group chooses the author for the next week's session.

\section{BEHAVIOR}

Now that we have discussed the roles in the writing group and the format of the writing group, we turn our attention to the behaviors and actions necessary for the writing group to achieve its goals. These observations come from our hands-on experiences with our writing group and clarify the responsibilities of the leader, the author, and the audience.

\section{A. Assembling the Writing Group}

Before considering any other part of the writing group, the leader must first get the writing group started. To start the writing group and get maximal attendance from the leader's research peers, it is important for the leader to get buy-in about the writing group idea from some of the students before proposing the creation of a writing group to the entire research lab.

In our case, the leader used a persuasion technique that originated in the business community called pre-wiring [5]. Before announcing the idea for the writing group to the entire lab, the leader personally met with the four students who had been with the research lab the longest to explain the concept and the specifics of the writing group. The goal here was to address any concerns from these students about the writing group and to get them excited about the idea. Then, when the idea was proposed to the entire lab, these four students chimed in that they thought the writing group was a great idea. We believe that using pre-wiring increased attendance and buy-in from the entire group.

\section{B. Ten-minute Teaching Session}

The leader begins the writing group by leading a ten minute lecture and discussion about a writing concept announced at the previous meeting.

After the leader lectures and explains the concept, there is an open discussion among the audience facilitated by the leader, focused on the concept. The conversation is meant to address any questions about the concept, to get each member of the audience thinking about how to apply the concept in their own writing, and also to identify areas where the lab's sub-field may apply the concept differently from the general scientific community.

\section{Twenty-minute Group Editing Session}

The group editing is supervised by the leader. The leader guides the group editing session to focus on the specific topic of the week. For instance, when the leader introduces the concept of the Introduction and how to structure an Introduction in a research paper, the author should be willing to share and discuss the Introduction of her research paper, and the audience should limit its analysis and feedback to the Introduction as well. While it is very useful to focus on the particular "concept of the week," it is equally important that the leader also allow other topics to bubble up organically from the audience.

The leader follows a format for the group editing session. First, the leader asks the author to read her text aloud to the audience. Having authors read their own work out loud is important. First, it is vital, especially for nonnative English speakers, for authors to get a feel for how the writing sounds [6]. The group picks up on sentences and phrasings that do not sound right. Also, places where the author stumbles while reading are possible red flags for revisions and improvements.

After the author reads the text out loud to the group, the leader asks the group for comments and suggestions about how to improve the writing. However, before asking for comments, the leader must make several things clear. First, the author is in complete control of the text and any changes suggested by an audience member are ultimately up to the author's discretion. At the same time, the leader should encourage the author to experiment with changes.

Another important thing that the leader should mention to the group is how nervous an author can feel when their writing is criticized. Therefore, the leader should ask that the group be respectful of the author's feelings when critiquing the text. At the same time, the leader should remind the author that the group is there to help, and that the author should not take comments about the writing personally. 


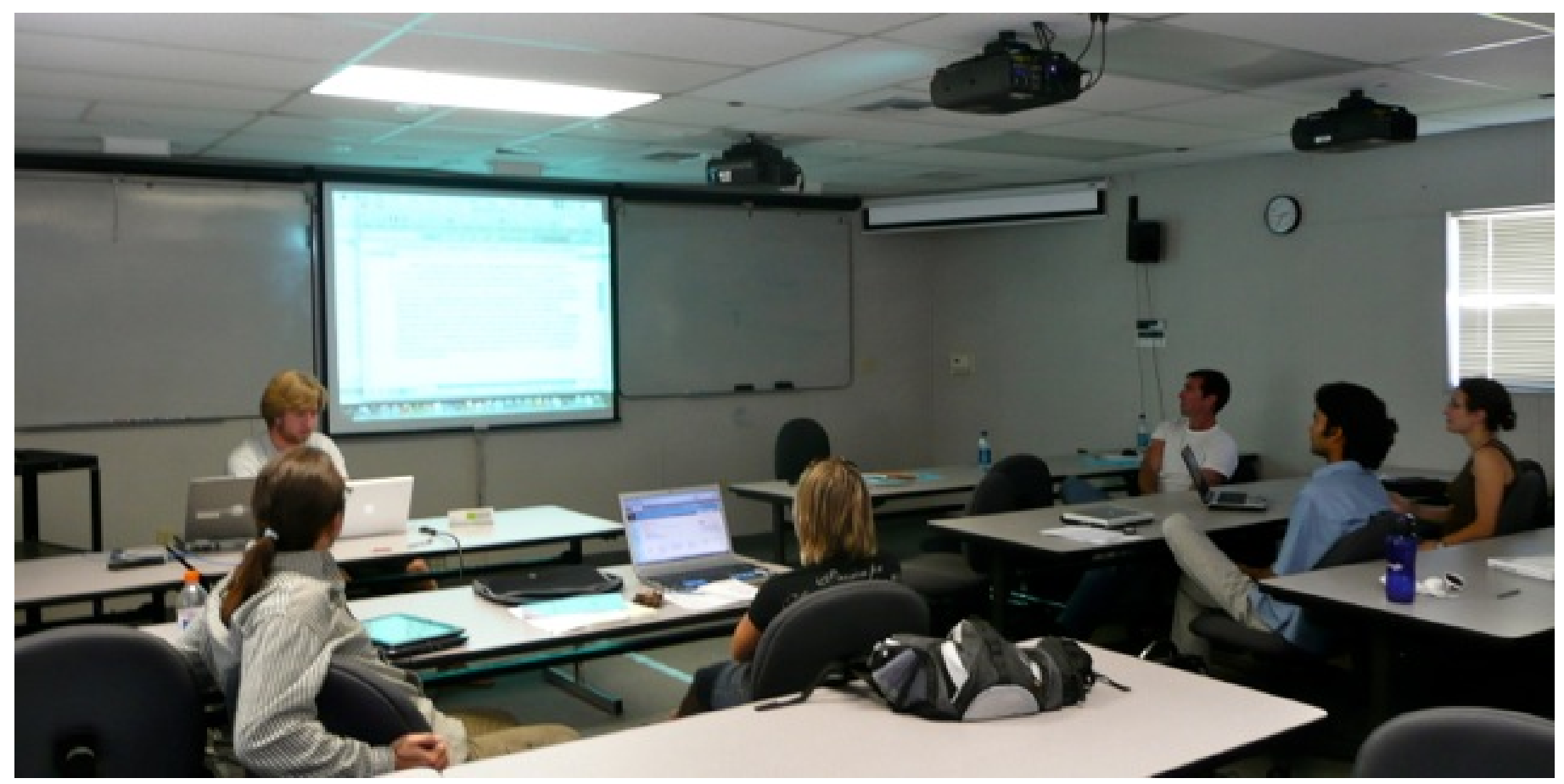

Fig. 1. Group editing session. Note how the author is situated in front of the group and that the author's text is presented on a screen for the entire group to easily read.

The group discussion is so valuable because it offers the writer the unique chance to receive insightful feedback from real readers. The responsibility of the audience, then, is to give helpful suggestions that advance the writer's story, the clarity, the organization, and the readability of the text. We are particularly fond of using Weissberg's approach to keeping audience comments "as specific as possible" [7].

Ideally, the leader lets the group and nature of the discussion develop in a natural manner. Of course, the leader should not hesitate to give her own opinion about the writing and what should be done. The leader must be aware, however, that because of her leadership role, others in the group may perceive the leader's opinion as carrying more weight. It is a subtle but very important aspect of the group dynamic that the leader should tread lightly with her own comments and feedback, and instead engage the group to focus on a specific area by asking leading questions about specific aspects of the text.

During the discussion, the leader should ensure that no one is dominating the conversation (including herself) and that everyone is participating. This can mean directly asking quiet members their opinions about the current topic or directing frequent contributors to let other students have a chance to speak.

We advocate a thorough and detailed approach to group editing. We talk about word choice, idioms, sentence restructuring, sentence combination, adding sentences, deleting sentences, adding connections, reducing repetition, and many other topics. We also play around with different variations and keep working at finding the right phrasing and sentence structure until the author and group are happy. We should also note that the author is not a passive participant in this process.
It is the responsibility of the author to take an active role in reworking the text by interacting with each group member who offers feedback.

\section{Choosing the Next Author}

An important component for the continuing success of the writing group is to have a different author present her work for the group editing session every meeting. The leader should ask, at the end of the current meeting, for volunteer authors for the next week. Some coercion may be necessary to identify a volunteer. It is vital that the leader get a student to verbally commit in front of all her peers to be the author for the next week [8]. This verbal commitment creates a social contract between the author and her peer group, increasing the likelihood that the student will take the responsibility seriously and be prepared to discuss her writing at the next meeting.

\section{LEADER FEEDBACK}

In this section, we discuss the leader's perspective on what can be improved with the writing group and what is going well.

\section{A. Cons}

The biggest drawback of the writing group approach as we implemented it was reliance on a single leader. Once the student had left the lab, no other student stepped up to take over the leadership role. We believe that in the future, reliance on a single leader can be mitigated by the leader actively recruiting assistant leaders to take over when necessary. The leader can ask the assistants to lead a writing group every few weeks, thus cultivating a group of students who feel confident and capable of leading the writing group in the original leader's 
absence. The reliance on one leader was probably the biggest drawback of the current approach, and when we started up the writing group again the leader made a conscious effort to build a group of capable leaders. Because of these capable leaders, this latest incarnation of the writing group has survived the absence of the original leader.

Everyone is busy (yes, even graduate students), so it is difficult to convince students to attend the writing group. Attendance would frequently dip close to a conference submission deadline, because the students are busy writing papers to meet the deadline. This problem is further compounded because all the students in the lab share the same deadlines. Hence, these deadlines can drop the attendance of the writing group significantly.

Unfortunately, as the leader is a peer of the students, she cannot force them to attend if they are busy. The best way to mitigate the effects of deadlines on the students' attendance is to demonstrate to them, before the deadline, that they will benefit greatly through a group editing of their work. The leader should choose authors to present their work for group edit even when they have a deadline. The rationale here, which must be explained to the authors, is that the authors will get the most out of a group editing session when their text is relevant and about to be submitted. Unfortunately, this approach is not fool-proof, as often before a deadline students are still running experiments rather than writing. Thus, they do not see the benefit of "wasting" a half hour to polish their writing when they still have experiments to run to complete the paper.

Another problem of the writing group is that the learning of the concepts and vocabulary necessary to be able to talk about student texts develops slowly. A shared vocabulary allows students to use statements like "I think that the tone of that paragraph is not appropriate for the given venue," rather than saying "That sentence sounds wrong." A better idea might be to spend more time, perhaps even the entire first meeting, going over the most fundamental writing terms and concepts. The risk here is that the students may lose interest in the writing group because they do not get to participate immediately in the interactive group editing session.

Finally, the role of leader is a huge responsibility. It requires out-of-group time to get things organized, and it asks for focused concentration and real-time teaching and leadership. These responsibilities of the leader are critical for the success of a writing group. At the same time, we want to point out that because the leader is teaching and guiding the group dynamics, she actually receives less benefit from the sessions that the rest of the group members.

\section{B. Pros}

Once everyone was on the same level of understanding concerning basic academic writing principles, the group editing sessions increased in efficiency, and we were able to cover more text. This shared level of writing vocabulary had ancillary benefits as well. We observed that the students who participated in the writing group used these concepts when working with each other on other papers. The benefit came not just from students collaborating on the same paper, but also when one student asked another to review or edit her individual paper.
While it is difficult for an author to bare her unfinished work to the world and subject it to the critique of other students, getting the students used to this kind of criticism and feedback was immensely beneficial. Once the students understood not to take the feedback personally, this tolerance and open-mindedness carried over to receiving feedback from others outside the group, including advisors and anonymous reviewers. Developing an open mind and a willingness to listen to feedback without becoming defensive, is an important skill not just in writing but in many other aspects of the career of a scientist.

A benefit for the authors when participating in the writing group editing session is that they learn to think through and justify their writing choices. Often, this process happens before the actual writing group takes place, as the author scrutinizes her work more carefully when she knows that it will be reviewed in the writing group.

During the group editing exercise, the group proposes changes to the author and the author decides to implement the changes or not. The author is encouraged to discuss with the group why she is making the change or why she is not making the change. Teaching authors to look at their own writing and justify the choices they make is an important writing skill, because good writing is all about choices, and a writer who is able to defend those choices, or has at least thought about the choices, will be more deliberate and clear with her writing.

Another huge benefit of the writing group is the transfer of knowledge from the "older" students to the "younger" students. Here, we are not referring to the age of the students, but rather to the length of time they have been in their graduate program. Older students have, on average, read more papers, written more papers, and have an understanding of how their specific field works. This means that the older students have a lot to teach the younger students.

Note that this transfer of knowledge is not limited to writing. Often, we see a lot of benefit from the writing group when older students explain to younger students the idioms and particulars of our field. There are also explanations and discussions about the different writing styles of our advisors. One specific example is our discussion about how one professor prefers to put the Related Work section at the end of a paper, rather than after the Introduction, which is more typical. We feel that this transfer of knowledge among students is critical to the development of the younger graduate students. It helps prevent them from making the same mistakes that the older students made in the early stages of their writing development. Another benefit is that the younger students pay attention to the points the older students make when they read new papers.

While our specific writing group meetings involve only the peers in our lab, a benefit of the writing group is the possibility to have an advisor or even a writing professor attend the meetings and participate in the writing group. The format of the writing group does not need to change to accommodate the newcomer. The beginning ten minute session might be replaced with a lecture from the experienced advisor about any topic related to writing. One caveat to address is that the leader should remind the new attendee, before the meeting and in private, to please consider their words carefully when critiquing the students' work, especially when the new attendee 
has role power over the student. It is essential for the openness and frank discussion that no student feel ashamed to make a comment because their boss or teacher is in attendance.

Finally, a writing group has a lot of benefit for students who are nonnative speakers of English. As long as there are a few native English speakers in the audience who have an ear for appropriate English usage and idioms, the nonnative speakers can benefit greatly. This transfer of knowledge is similar to the transfer of knowledge from older students to younger students. The native speakers can help the nonnative speakers with the subtleties of English. Specific areas of attention are word choice and phrases or sentences that, while grammatically correct, are not the common or correct way to express a thought.

\section{Student FEEdBACK-IN ThEIR OWN WORDS}

We asked the students who have participated in the writing group the following three questions: (1) What specifically about the writing group did you find valuable? (2) What would you change about the writing group? (3) Are there any other information or inspiring quotes you'd like to share about writing or the writing group? We selected some of the student comments to share here to provide insight into their experiences with the writing group.

One first-year PhD student wrote that the most valuable part of the writing group was gaining insight into the writing process:

You see how everybody (even the good writers) are struggling to write even a single paragraph: If you are a bad writer and your writing skills-related selfconfidence is near zero (i.e., me), it's a huge help to boost your confidence! Writing is hard. Period. It's good to know.

I believe everybody should develop his own writing process: When you don't have one, it's really useful to see how the good writers are actually producing a good paragraph of text! In fact, you are usually able to just "read" a good paragraph, but you don't know what the process is behind it (the really important part).

A third-year PhD student appreciated seeing other students' viewpoints and how they criticized a text:

I liked to see how others criticize a piece of writing. It certainly widened my view. Particularly, knowing why someone prefers a piece of text to be written in a certain way helps considerably.

I like to hear the unedited version of why others like a style of writing. I prefer their comments to be more about why they personally like it, and not the cliché formatting bugs. This way I can recognize what most people like and why they like it, and not only a standard way of writing (which, by definition, is one of many ways you can write a good text). The personal feedback enables me to change my style more freely, without religiously sticking to unbendable formats.
Another first-year $\mathrm{PhD}$ student commented on specific topics that we covered, particularly about the organization of a paper:

The discussion we had about the paper's organization was really valuable as well. For example, understanding that there is no fixed-rule about where to put the Related Work section is a good thing to know. More in general: Bad writers (me) need to understand which rules are "fixed" and, more importantly, which are not!

For improvements to the writing group, one second-year student wanted more focused meetings:

[An improvement could be] small themed meetings. Like we pick a specific topic (how to connect paragraphs for example) and we speak about it and work on some sample texts. Specifically if we do it on our own papers it will help a lot and improve our writing.

\section{CONCLUDING REMARKS}

The goal of the scientist is to share and spread her ideas. An exceptional scientist will write her thoughts clearly and express her ideas elegantly, creating a persuasive story that is readable and interesting to her audience. We believe that developing a culture of excellence in writing should be a fundamental aspect of graduate school education. To achieve this lofty goal, we require new ways of teaching writing skills to train the next generation of scientists who will make breakthroughs we can only dream of.

A research lab writing group, as discussed in this paper, is a novel approach to helping graduate students develop the tools necessary to refine their formal writing skills. In fact, if you have a single student who has completed an advanced writing course who is motivated to form a writing group, an entire research lab can participate in what realistically amounts to a mini-writing class.

We hope you steal our ideas and adapt them to your own research lab. Together we can improve the writing of graduate school scientists in labs all over the world.

\section{REFERENCES}

[1] J. Kayfetz and K. Almeroth, "Creating innovative writing instruction for computer science graduate students," in Frontiers in Education Conference, 2008. FIE 2008. 38th Annual, 2008, pp. T4F-1-T4F-6.

[2] J. M. Swales and C. B. Feak, Academic Writing for Graduate Students: Essential Tasks and Skills. University of Michigan Press Ann Arbor, MI, 2004, vol. 1.

[3] M. desJardins, "Case Study: Teaching Research Skills to Computer Science Graduate Students," in Proceedings of the 3rd International Conference on Education and Information Systems, Technologies and Applications (EISTA 2005), Orlando, FL, 2005.

[4] D. G. Kay, "Computer Scientists Can Teach Writing: An Upper Division Course for Computer Science Majors," in ACM SIGCSE Bulletin, vol. 30, no. 1. ACM, 1998, pp. 117-120.

[5] M. Horstman and M. Auzenne, "How to Prewire a Meeting," Podcast, November 2007. [Online]. Available: http://www.managertools.com/2007/11/how-to-prewire-a-meeting

[6] L. Dupré and L. S. Crapsi, BUGS in Writing: A Guide to Debugging Your Prose. Addison-Wesley, 1995. 
[7] B. Weissberg, "A Collaborative Model For Facilitating Writing Workshops," Presented at TESOL 2004, April 2004.

[8] M. Horstman and M. Auzenne, "Influence Through Verbal Commitments - Part 1," Podcast, April 2010. [Online]. Available: http://www.managertools.com/2010/04/influence-through-verbal-commitments-part-1 